\title{
Mapping energy-efficient technological advances in home appliances
}

\author{
Nicolò Barbieri $\mathbb{D}$ - Alessandro Palma
}

Received: 11 June 2015 / Accepted: 8 August 2016

C) Springer Science+Business Media Dordrecht 2016

\begin{abstract}
The present study employs patent data on three groups of large energy-efficient appliances (i.e. freezers/refrigerators, washing machines and dishwashers) and provides a methodology for (i) mapping components related to energy efficiency improvements, (ii) mapping their evolution over time and (iii) testing the technological fungibility of these components. Our analysis model exploits an original patent selection process and the concept of technological relatedness using co-occurrence analysis of patent classes as input for selforganising maps (SOMs), an unsupervised artificial neural network able to represent high-dimensional data in a visually attractive and two-dimensional distancebased map. The results confirm the pervasive nature of energy efficiency to be nested in many technological components. In addition, we show that a dematerialisation process has affected the evolution of energy efficiency technologies over time, in a technology space
\end{abstract}

N. Barbieri

Department of Economics and Management, University of Ferrara, Via Voltapaletto 11, Ferrara 44121, Italy

N. Barbieri $(\square)$

SEEDS - Sustainability Environmental Economics and Dynamics Studies, Via Voltapaletto 11, Ferrara 44121, Italy

e-mail: brbncl@unife.it

A. Palma

IEFE, Bocconi University, Via Roentgen 1, Milan 20136, Italy

e-mail: alessandro.palma@unibocconi.it

A. Palma

CEIS, Faculty of Economics, University of Rome "Tor Vergata", Via Columbia, 2, Rome 00133, Italy characterised by a high level of complexity and variety. Energy efficiency has links with information technologies embodied in the appliances, which are far from their maturity path. Consequently, innovation and information policies are of utmost importance in order to achieve more ambitious energy efficiency targets in the groups of appliances analysed.

Keywords Energy efficiency · Self-organising maps · Patent analysis · Home appliances · ICTs

JEL classification Q55 $\cdot \mathrm{Q} 41 \cdot \mathrm{O} 33$

\section{Introduction}

The reduction of primary energy consumption through energy efficiency (EE) represents a cornerstone of the transition towards a resource-efficient green economy in Europe and an effective strategy to achieve energy independence (EC, 2011). Nevertheless, energy saving and $\mathrm{EE}$ are not completely overlapping terms since $\mathrm{EE}$ is a sub-set of the energy saving (or energy conservation) domain. The latter is a broader concept since energy saving can be obtained through gains in EE or by simply reducing the level of economic activity. According to Patterson (1996), EE is the relationship between the output and the energy consumed to produce it, often called energy service. Thus, a general characteristic of $\mathrm{EE}$ is the use of less energy inputs for an equivalent level of economic activity or service (Gillingham et al., 2009) so that achieving higher EE performances intrinsically 
relies on the dynamics of technological innovation as a means for improving productivity of the energy input and reducing the associated energy consumption (Rennings and Rammer 2009; Florax et al., 2011).

The attention received by the residential sector in the analysis of efficiency gain grew significantly in recent years. The rise of household electricity demand driven by penetration of electrical appliances of different nature such as PCs, TV and portable ICT devices together with socio-demographic changes (Bertoldi and Atanasiu, 2007 ; Atanasiu and Bertoldi, 2008) has raised government concern across the EU because such an increase can threaten their efforts to reach the targets set out under the recent EU 20-20 strategy. At household level, the widespread presence of traditional large appliances (e.g. freezers, refrigerators, washing machines and dishwashers) is still responsible for $25 \%$ of households' electricity consumption as opposed to other appliances such as information and communication devices whose energy needs are negligible with respect to the so-called white goods (Saidur et al. 2007).

Even though traditional electrical appliances are characterised by mature technologies, their potential contribution to reducing aggregate energy consumption is still very large if we consider the combined effect of EE improvements in these technologies and the fact that, since traditional appliances are crucial to fulfilling primary needs, they are largely widespread among household dwellings (IEA 2009, 2012; EC-JTR, 2012). Recent studies have confirmed cost-effectiveness of EE gains deriving from electrical appliances with respect to those deriving from other sectors. In particular, cold appliances (freezers and refrigerators), washing machines and dishwashers seem to have had a large impact in terms of EE performances (McKinsey and Company 2009; Hyung et al., 2006) ${ }^{1}$ and such an impact clearly reflects the increased effort of governments in implementing new EE regulation. Among others, it is worth mentioning the Eco-design Directive (Directive 2009/125), the Energy Labelling Directive (Directive 92/75/EC, replaced by Directive 2010/30) and the Montreal Protocol on Substances that Deplete the Ozone Layer, agreed in 1987 within the Vienna Convention and entered into force on 1989. This latter envisaged the

\footnotetext{
${ }^{1}$ The portfolio of energy services available for households has massively increased over the last 20 years, with a strong penetration of new devices and appliances aimed at satisfying these services. See Burwell and Sweezey (1990).
}

gradual phasing out of chlorofluorocarbons largely employed in older refrigerators and freezers ${ }^{2}$.

In this setting, the contribution of technical change for increasing the efficiency of energy-intensive devices is key to reducing the electricity consumption in the residential sector. In this respect, several studies analysed the economic implications of more efficient appliances (Datta and Gulati, 2014; Filippini et al., 2014; Galarraga et al., 2011a; b ; Galarraga et al., 2016 ). A detailed and interesting attempt to measure the impact of new efficient appliances is provided in Borg and Kelly (2011), who used high-resolution demand data reflecting the effects of EE improvements in appliances in future years. As a consequence of the changeover in favour of more efficient appliances, they estimate an average reduction in electrical consumption of $23 \%$ at 2020 for the households under investigation.

Although the evidence on the impact of energyefficient appliances signals a consistent and large beneficial effect in terms of electricity saving, most of these studies do not focus on the impact of technology, which is often considered implicit (e.g. analysing energy classes based on the performance of energy consumption or some basic product characteristic) and with a raw representation of the complex portfolio of available technologies. At the same time, it is acknowledged that traditional electrical appliances have shown a growing level of technology integration, as more and more appliances incorporate information and communication technologies (ICTs) such as stand-by devices, real-time displays, intelligent sensors, smart meters and advanced firmware as well as many other improvements which allow for more sophisticated food conservation and washing processes. Martiskainen and Coburn (2011) emphasised that ICTs can both enhance and decrease energy consumption, the former through the use of energy to operate (Koomey, 2007) and the latter due to increased awareness of households on their energy consumption and improved EE performances. Moreover, the steady technological advancement of electrical appliances is strongly linked to the concept of Smart House, in which a large use of ICTs is required to facilitate the interoperability of household products and services (Peine, 2009). In a smart house, different products are mutually linked and controlled through a bus system, thus imposing the presence of ICTs in addition to traditional mechanics. In

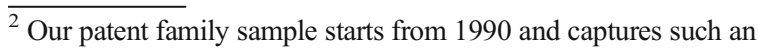
important regulation.
} 
this respect, Antonelli states that 'no product or process can be manufactured without the substantial application of new information and communication technologies or without substantial effects of the application of new information and communication technologies' (Antonelli 2003, pp. 598; see also Antonelli 1992a, b) and identifies fungibility as a further element characterising the ICTs. The concept of fungibility applies to technologies with applications that are useful to a great array of new products and processes and is strictly related to the concept of general-purpose technologies (Bresnahan and Traitenberg, 1995; Rosenberg and Trajtenberg, 2004; Bresnahan, 2010). In this regard, Panzar and Willig (1981) highlighted some important futures of general-purpose technologies, such as lower production costs due to joint use of appliance components and gains in production efficiency through scope economies. According to Corrocher et al. (2007), ICTs are largely seen as one of the most important generalpurpose technologies, able to spur the development of new technologies and applications spreading across different sectors.

The higher degree of technological variety as well as the increasing level of ICT integration raises a series of questions and issues to be analysed which constitute the object of this paper. In particular, given the increasing technological complexity embodied in appliances and their strong contribution to decreasing household energy consumption, it is worth analysing the technological structure and evolution of EE in energy intensive electrical appliances. This implies a decomposition of the technology space in which EE has nested and evolved over time. In addition, we aim to analyse which role, if any, ICTs have played in transforming the technology space of energy-efficient domestic appliances.

Building on this debate and by employing an original dataset of 688 unique triadic patent families ${ }^{3}$, we breakdown the technology space of three groups of energyefficient domestic appliances (i.e. freezers/refrigerators, dishwashers and washing machines) into different

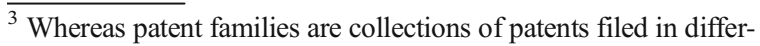
ent patent offices and related to the same invention, Triadic Patent Families are inventions protected in the main patent offices: European Patent Office, Japanese Patent Office and US Patent and Trademark Office. The use of Triadic Patent Families enhances the quality of patent datasets since the influence of rule and regulations of patent offices and patenting strategies are reduced (Dernis and Khan, 2004). Further details are provided in the "Sample selection" section.
}

technology clusters that are able to affect EE performances. Subsequently, we map and identify these clusters of patents related to EE technologies and unveil their dynamics over time and across appliances. In doing so, we exploit patent maps obtained through the implementation of self-organising maps (SOMs), a class of unsupervised artificial neural network able to represent high-dimensional data in visually attractive and lowdimensional distance-based maps (Kohonen, 1990, 1998, 2001, 2013).

The rest of the paper is organised as follows. The "Patent analysis model" section, after a brief introduction of the main methods to build patent maps, describes the sample selection and the patent analysis model, along with the theoretical foundations of SOMs. The "Results and discussion" section presents and discusses the results. The "Conclusions" section concludes the paper.

\section{Patent analysis model}

There are several possibilities for measuring technological advances. As with most economic variables, the problem of measurement is directly related to the availability and the quality of specific data. Patent data provide a public wealth of information suitable to study environmental technological change (Popp, 2005). The role of patents has been largely exploited since they allow specific technology features to be analysed (among others: Griliches 1990; Archibugi and Pianta 1996; Leydesdorff et al. 2014). Indeed, patent data include, among others, information on the geographical location of the applicant or inventor, citations to prior patents and, most importantly for the purposes of the present study, the technological specification of each invention for rather long time series. However, the use of patents as a proxy of inventive activity was not exempt from criticism regarding, for instance, heterogeneity in their technical and economic value (Griliches 1998; Hall et al. 2005) and differences in the propensity of patenting across sectors and technologies (Arundel and Kabla 1998). A further limitation of patent data is represented by the partial and rough representation in the set of international patent classification when technological domains characterised by high complexity and rapid evolution are under scrutiny. Such an issue becomes crucial in eco-innovation studies since a growing number of green technologies are being developed and mapped by researchers and practitioners through ad 
hoc methodologies, as in the case of biofuels in Costantini et al. (2013).

When patents or patent families are used to investigate technology dynamics, the outcome usually takes the name of patent analysis. The broad set of methods and techniques related to patent analysis aims at identifying coherent information for different purposes. Basically, patent analysis techniques automatically reduce the large amount of information provided by patent documents to useful low-dimensional information. A taxonomy of the main patent analysis tools is proposed by Abbas et al. (2014), which distinguishes between data processing using text-mining techniques and visualisation maps. Indeed, the information in patent documents is provided by structured and unstructured patent item (Lee et al., 2009; Tseng et al., 2007). The former includes standardised elements retrieved in patent documents, such as technological classes, priority year or citations count, whereas the latter, i.e. unstructured patent items, contains free text strings. Since the innovative content is enclosed in the text corpus of patent documents, the analysis of unstructured data employs text-mining techniques as a means of knowledge extraction. Tseng et al. (2007) emphasises that the creation of patent maps using unstructured items follows different steps. After a first phase in which relevant patents are collected, text mining techniques parse the text corpus of patent documents from which representative keywords or phrases are extracted and indexed in order to characterise each word. In the following step, a clustering tool is applied to reduce the complexity of the information retrieved, detecting the knowledge structure of the dataset. Finally, visualisation methods are used to show graphically the results of this process.

Unstructured items are usually analysed through different approaches detailed by Abbas et al. (2014). Some of them are (i) natural language processing approach, usually employed to retrieve the grammatical structure (e.g. keywords and their relationship) in patent documents; (ii) property function-based techniques, used to identify the technological connotations of patent and detect codified properties in their textual data though natural language processing; (iii) rule-based approach that measures associations between grammatical structures employing inference rules and association rules among unstructured items; (iv) semantic analysis-based techniques applied to identify similarity between patent technological contents through the creation of logical relationships between parsed grammatical structures and (v) neural network-based technique used to filter information in textual data through the use of backpropagation neural networks.

Visualisation maps (patent mapping) also constitute an important part in explorative patent data analysis, especially with high information complexity and data dimensionality (Vesanto 1999). In this respect, the representation of patent analysis using maps is widespread in the literature of patent analysis and there are numerous techniques devoted to this aim. Broadly speaking, a patent map ${ }^{4}$ is able to show complex and invisible relationships between different patent documents as well as their peculiar features by exploiting a simpler low-dimensional visualisation.

Furthermore, Abbas et al. (2014) classifies patent maps as patent networks and cluster-based maps. In a patent network, the relationship between objects is investigated by analysing the characteristics of nodes (e.g. patent documents) and arches connecting them (e.g. citations between patents) (Barberá-Tomás and Consoli, 2012; Epicoco, 2013). Although network analysis was initially employed in sociological studies, such methodology now represents a widespread technique in innovation economics with a number of tools for visualising and interpreting both structured and unstructured patent items (Narin 2000; Huang et al. 2004; Yoon 2004; Verspagen 2007; Sternitzke et al. 2008; Lee et al. 2009, among others). Finally, a patent map can also derive from a clustering process in which observations are divided into groups 'internally homogeneous (internal cohesion) and heterogeneous from group to group (external separation) [...] reducing the space dimensionality' (Giudici 2003, pp.76; see also Kim et al. 2008). For instance, the principal component analysis is a suitable technique to reduce the number of keywords and therefore the size of the keyword matrix from which the map is generated. Lee et al. (2009), after listing keywords included in the patent dataset through text mining, employed principal component analysis to decrease the number of keywords in order to build a patent map and detect new technology development and new product creation trends.

Patent maps may also differ in the outputs they produce. Van Eck and Waltman (2010) distinguished between graph-based maps and distance-based maps. While the focus of the former is on the presence of links

\footnotetext{
${ }^{4}$ Map is here used as a generic term, being synonymous with diagram, chart or graph.
} 
between items (e.g. patent networks), the latter captures the strength of these relationships and projects them in a spatially ordered space that captures the relatedness between objects. In this class of maps, the similarity between the input data is measured and represented in a low dimensional space where, usually, the lower the distance between the items, the greater their similarity. A promising approach to build patent maps relies on the use of artificial neural networks which have shown a high level of efficiency in managing high-dimensional observed data. Among the different types of artificial neural networks (surveyed in Giudici, 2003), the present study employs self-organising maps (SOMs), an unsupervised neural network technique able to reduce the dimensionality of the input data and represent them in a two-dimensional space (Kohonen, 1990, 1998, 2001, 2013). SOMs are based on unsupervised learning processes able to map every dimensional observation in a spatial grid (see the "SOM implementation" section for a comprehensive description of this method). Such a feature makes the SOM particularly effective for classification and clustering analysis. Indeed, nodes are placed in such a way that adjacent ones will be more similar than the distant output nodes, thus introducing a topological dependence between clusters and preserving spatial correlation between the input vectors and the clusters.

The use of SOMs has been increasingly adopted in several applications and for mapping different types of data, such as, for instance, scientific journal networks (Campanario, 1995), author co-citation data (White et al. 1998), conferences (Silva Almendra et al. 2014), firm technological efforts (Barbieri 2015) or industrial districts (Carlei and Nuccio 2014). A version of the SOM, i.e. WEBSOM, has been implemented to build topically ordered maps in which large amounts of documents are located in relation to their textual data (Lagus et al. 2004). In addition, several papers employed patent data to visualise technological landscapes (Park et al. 2013; Polanco et al. 2001; Lee et al., 2009). Yoon et al. (2002) applied SOMs in order to show complex relationships and dynamic patterns in different technologies. They built technology vacuum, claim point and technology portfolio maps to identify technology-missing areas, potential infringements and technology classifications, respectively. A further recent contribution employing text-mining techniques and SOMs is provided by Segev and Kantola (2012) who used a term frequency-inverse document frequency algorithm to extract patent knowledge then represented by SOMs.

Despite the increasing number of studies that use citation data and connectivity analysis (Verspagen 2007, among others), the present paper relies on SOM to unveil the domains of EE technologies. The reason for our choice is twofold. First, the characteristics of EE technologies may permeate many technological domains decreasing the usefulness of using citation data to detect these domains. In addition, the use of citations would underestimate the technological content in most recent patents, considering that these show lower probability to be cited than older patents (Jaffe and Trajtenberg, 2004). In this respect, the choice of using patent classification codes instead of citations allows us to exploit a longer time series. Building on these contributions, our patent analysis model (Fig. 1) is characterised by three phases. The first phase, i.e. pre-processing, is devoted to obtaining a set of patents belonging to energy-efficient electrical appliances while the last two, i.e. processing and post-processing, aim to identify the technological clusters in which EE is nested, as well as analysing their technological evolution over time.

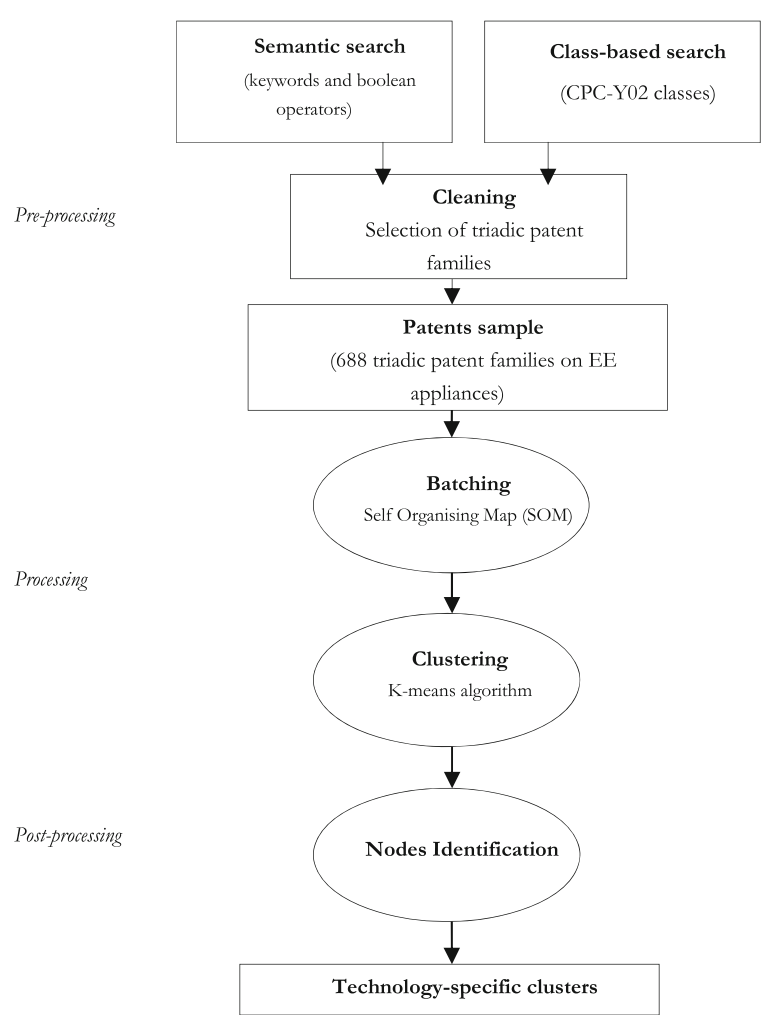

Fig. 1 Patent analysis model 
Sample selection

By employing patents to study technological advances, we are focusing on inventive activities that characterise the early stages of technological change (Schumpeter, 1942) in which ideas are born. Even though this does not imply that our set of patents have reached commercial application, the paper aims to identify the main technological advances in the field of energy-efficient appliances which entails that excluding patent without commercial application would limit the capabilities of our analysis to understand the dynamics of more recent technologies still in their early stage of development.

The coherent set of patent documents on which the empirical analysis builds on is collected using an original patent search process based on keyword and patent classification codes ${ }^{5}$. Only since 2013 did the Cooperative Patent Classification (hereafter referred to as CPC) include classes related to $\mathrm{EE}$ technologies for domestic electrical appliances ${ }^{6}$. According to Costantini et al. (2014), the reason for such a lack is twofold. First, EE appears a latent technological domain since improvements in EE are not always explicitly mentioned by the main unstructured items of patent documents, namely title, abstract and claims. Consequently, the full document text, including long patent descriptions, must be analysed. The second reason lies with EE pervasiveness, the

\footnotetext{
${ }^{5}$ Patents were downloaded using 'Thomson innovation database' (December, 2014)

${ }^{6}$ The Cooperative Patent Classification was established in 2010 as a joint partnership between the US Trademark and Patent Office (USPTO) and the European Patent Office (EPO) to provide harmonisation between the two classification systems developed by each office, European Classification and US Patent Classification, respectively. This classification system provides an international classification standard aimed to harmonise the search process of patents based on their technological content. When patents are filed by, the patent office assigns the CPC codes in order to describe the technological content of the invention. This classification system is based on the International Patent Classification (IPC) and it has a hierarchical structure. This means that as far as the number digits of the CPC code increases, its technological specification grows. For example, the four-digit code Y02B refers to 'Indexing scheme relating to climate change mitigation technologies related to buildings, e.g. including housing and appliances or related end-user applications' and the eight-digit code Y02B0040 relates to 'Technologies aiming at improving the efficiency of home appliances'. Whereas the former includes the latter, the specificity of Y02B0040 is higher than the one of Y02B which includes a higher number of technologies, such as 'integration of renewable energy sources in buildings' (Y02B0010), 'energy-efficient lighting technologies' (Y02B0020), etc.
}

Table 1 Energy efficiency triadic patent family sample, by appliance

\begin{tabular}{lrr}
\hline & Patents & \multicolumn{1}{l}{ Share } \\
\hline Dishwashers & 66 & $9.60 \%$ \\
Freezers/refrigerators & 489 & $71.08 \%$ \\
Washing machines & 133 & $19.33 \%$ \\
& 688 & $100.00 \%$ \\
\hline
\end{tabular}

characteristic to be embodied in many components and devices. Indeed, an analysis of the relationship between $\mathrm{EE}$ and technological content shows that EE not only operates in the most advanced technologies but, comparatively, in the entire panorama of technologies using energy. In the field of patent analysis, this means that EE represents a complex cross-cutting technology space in which many CPC classes are involved in order to increase the efficiency of devices. Given the partial representation of the new CPC classification, a specific methodology for identifying EE technologies using patents is strongly required (see also Noailly and Batrakova 2010).

The patent search process that we followed in the paper combines a top-down and bottom-up approach for catching patents filed at several patent offices. The topdown search method employs the recent CPC-Y02B-40 classes, defined as 'technologies aiming at improving the efficiency of home appliances'. These include specific sub-classes referring to EE technologies in electrical appliances such as thermal insulation for freezers or heat recovery devices for dishwashers (see Appendix Table A1). Nonetheless, CPC fails to capture different technical expedients able to increase appliance efficiency, such as for instance, lighter motion devices deriving from the use of new materials or more efficient refrigerant liquid in cooling appliances. We filled this gap in the bottom-up search approach by employing two levels of searching with selected keywords together with Boolean operators (AND, OR, NOT) as in Costantini et al. (2014). Considering the latent nature of EE technologies, two search levels were performed on the full patent-unstructured items (title, abstract, claims and description). The first level defines the EE macro-domain with respect to the universe of patent applications in the considered period, whereas the second level reduces the macro-domain to an end-use level on those patents classifiable as inherent to domestic electrical appliances such as 'refrigerator', 'washing machine' and so on ${ }^{7}$.

\footnotetext{
$\overline{{ }^{7} \text { Search strings }}$ are provided in Appendix Table A2
} 
Table 2 Number of patents related to energy efficiency technologies and their CPC code standard deviation (SD) for each sampling approach

\begin{tabular}{lccc}
\hline & Top-down approach & Bottom-up approach & Combined Approach \\
\hline Number of patents & 42 & 659 & 688 \\
Full CPC code SD & 4.490 & 9.748 & 9.567 \\
8-digit CPC code SD & 2.282 & 3.152 & 3.122 \\
4-digit CPC code SD & 0.975 & 1.187 & 1.164 \\
\hline
\end{tabular}

Therefore, we reduced the set of applications to three groups of energy-intensive electrical appliances: freezers/refrigerators (cooling appliances), washing machines and dishwashers (washing appliances).

The patents obtained by the combination of a topdown and bottom-up approach are then used to collect patent families ${ }^{8}$. Furthermore, in order to increase the quality of our dataset with higher value patents and improve their international comparability, the analysis employs triadic patent families as unit of analysis (Martinez, 2010; Dernis and Khan, 2004). The resulting dataset includes triadic patent families whose patents are applied to the main patent offices ${ }^{9}$, i.e. European Patent Office, Japanese Patent Office and US Patent and Trademark Office. Although the use of triadic patent families reduces the patent sample, it positively affects the quality of the dataset since the cost for seeking patent protection in many countries is associated with higher application fees that are not likely to be incurred for low-value inventions. Patent application does not imply that the patent will be granted because only a portion of patent applications fulfils patenting criteria, such as novelty, industrial applicability, etc. However, using triadic patent families based on patent application, instead of granted patents, would avoid a further reduction of the patent sample and increase the timeliness of the data. In this respect, Dernis and Khan (2004) emphasise that focusing on triadic patent families calculated using granted patents would further reduce the number of patent families at the European Patent Office of at least one quarter, with a larger reduction in other patent offices (e.g. Japanese Patent Office). Moreover, using grant data

\footnotetext{
${ }^{8}$ This procedure allows the double counting of patents that refer to the same technology whose protection had been extended to many patent offices to be dropped.

9 Triadic patent families put together patent applications filed at the European Patent Office and Japanese Patent Office. Due to the fact that until 2001 the US Patent and Trademark Office did not provide data on patent application but only on granted patents, the latter is used as a proxy for patent applications in that office (Dernis and Khan, 2004).
}

would affect patent time series since "the grant process takes on average between 3 to 4 years at the US Patent and Trademark Office and 5 years at the European Patent Office (in some instances, the grants process last up to ten years)' (Dernis and Khan, 2004: pp. 19). Partially related to this issue, the use of patent applications reduces the time lag between development and disclosure of the invention improving the accuracy of the results.

We obtained a dataset of 688 energy efficiency triadic patent families filed from 1990 to 2014 and related to three groups of domestic appliances as shown in Table 1. As a final step, we tested a sample of $15 \%$ for each appliance analysed as a further manual validation process.

The advantages of using both $\mathrm{CPC}$-search and stringsearch approaches are manifold. First, as shown in Table 2, the results obtained from a combination of the two methods are complementary since the use of only one of them would not capture some EE patents in the considered appliances. In particular, when the search process to collect EE patents is carried out using the top-down approach, a large portion of patents is missed. This latter is, on the other hand, captured by the bottom-up approach. Moreover, if we consider the number of CPC codes per patent as a proxy for technological diversification $^{10}$, the top-down approach shows a lower level of variety as measured by the standard deviation of CPC codes per patent, which is higher for those patents collected through a semantic search (keywords). This confirms the latent nature of the EE technological domain and provides evidence of its pervasiveness, given that the general objective of EE spreads across several classes as already highlighted in Noailly and Batrakova (2010) and Costantini et al. (2014).

A further validation method for capturing the pervasiveness of EE in different technological areas is based

\footnotetext{
$\overline{{ }^{10} \text { Breschi et al }}$. (2003) employed the number of technological classes (that patents belong to) as a proxy for firm technological effort diversification. In our paper, we adopt a similar approach using patents as the observation unit (instead of firms). We assume that the higher the number of CPC codes assigned to each patent, the greater their technological diversification.
} 
Fig. 2 Technology space obtained through four-digit and eight-digit CPC code cooccurrence


on a graphical analysis of the technology space of freezers/refrigerators obtained with four-digit and eight-digit CPC co-occurrence maps for the collected sample. In Fig. 2, each map's node represents a single CPC class and it is located according to its similarity with the other nodes. Figure 2 is a distance-based map that captures the relative importance of the CPC codes with respect to the other nodes (van Eck and Waltman, 2014). In this two-dimensional space, the similarity between nodes constitutes the mapping rule. Smaller (larger) distance indicates higher (lower) similarity between nodes ${ }^{11}$. Hence, more central nodes have greater co-occurrence levels with other CPC classes. As shown, the portion of the technology space captured by the

\footnotetext{
${ }^{11}$ The maps are built using VOS mapping technique (Van Eck and Waltman, 2010) implemented in the freely available software used to map bibliometric items called VOSviewer (http://www. vosviewer.com). The construction of the map follows three main steps. First, a similarity map is built using a normalised cooccurrences matrix. Second, the VOS mapping technique is implemented and each node is mapped so that the distance between each pair of nodes reflects their similarity. Third, VOS performs translations, rotations and reflections to the resulting map.
}

bottom-up approach (red line) is larger than the one obtained by using only a top-down approach (blue line), the latter only representing a subset of the former. However, despite the fact that the top-down approach fails to catch EE peripheral technological areas, it captures the most important CPC classes, located in the central part of the maps, since it is characterised by a high degree of co-occurrence.

\section{SOM implementation}

In order to create the patent map, we apply the selforganising map (SOM), a topological ordered mapping technique firstly introduced by Kohonen (1990) (see also Kohonen, 1998, 2001, 2013). This tool is an unsupervised competitive artificial neural network able to represent multidimensional data on a two-dimensional topological grid (Kohonen, 2001). Such a technique reduces complex non-linear statistical relationships into a simpler, easy to understand and graphically attractive low-dimensional map in which the topological relationship between input data, which tend to be clustered, is preserved (Kohonen, et al. 1996). 
Fig. $3 \mathrm{CPC}$ codes counts and number of CPC codes never explored before over time (fourdigit CPC codes)

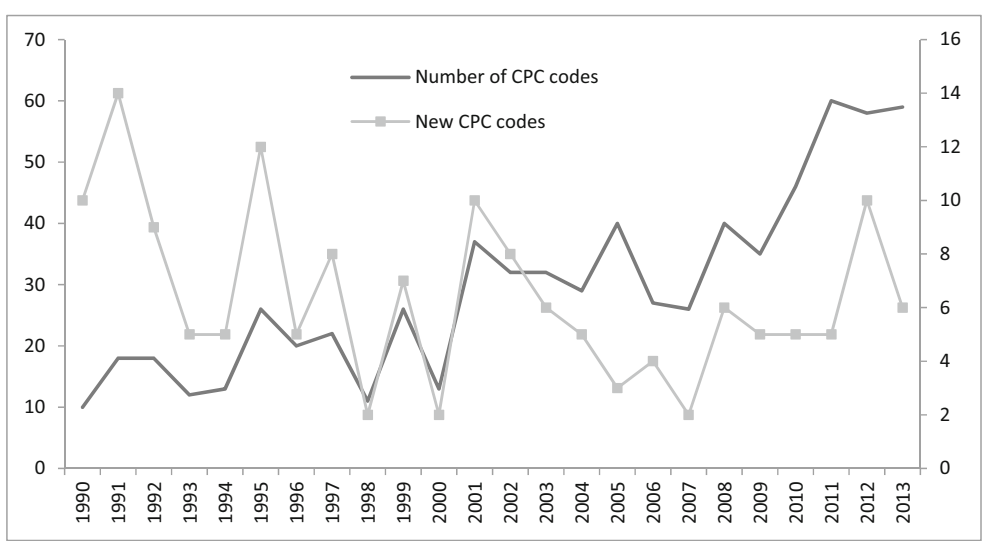

By resembling the vector quantisation process ${ }^{12}$, the SOM is a suitable tool for multidimensional reduction which provides a spatial and global order within the output map since similar input data are placed closer in the map and different input data gradually further away (Kohonen, 2013). Such a feature is provided by the adaptive units that form the map and are able to modify their response in such a way that the position of the nodes in the map becomes representative of the patterns found in the inputs (Yoon et al., 2002). In addition, SOMs are able to learn from input data for a more effective representation and dimensionality reduction.

To build the SOM, we employed the SOM Toolbox ${ }^{13}$ using the batch algorithm that provides higher accuracy as well as lower computational efforts (Kohonen, 2013). The batch algorithm is calculated as follows:

1. Define map dimension ${ }^{14}$ and assign map node weight vectors (initialization phase).

2. Select single input vector from the dataset.

\footnotetext{
$\overline{12}$ A standard methodological tool in modern digital signal processing in which $n$-dimensional input vectors are assigned to contiguous regions, each of them represented, in an optimal way, by codebook vectors

${ }^{13}$ A free Matlab@ function package developed by the SOM Toolbox Team at the Helsinki University of Technology (Vesanto et al., 1999). The SOM Toolbox is downloadable under GNU General Public Licence at: http://www.cis.hut. fi/projects/somtoolbox/. SOM Toolbox is copyright (C) 20002005 by Esa Alhoniemi, Johan Himberg, Juha Parhankangas and Juha Vesanto.

${ }^{14}$ We employed a heuristic formula proposed in the SOM Tool-

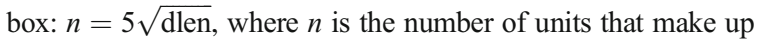
the final map and dlen the number of observations that are mapped. As stated above, the shape of the lattice is defined by the two largest Eigen vectors of the training data, during the initialization phase.
}

3. Identify the most similar map node to each input data (the one that minimises the Euclidean distance between the input and map vectors) and track it as best matching unit.

4. When all input data are assigned to their best matching unit, update the weight of each map neuron by computing the mean of the input data placed in the kernel defined by the neighbourhood function.

The batch algorithm differs from the classical sequential algorithm in the way input data are presented to the grid of neurons since the whole set of input data is presented to the map in one step, and only subsequently are the map weights adjusted to reproduce the similarity between them. In this way, the order in which the input data are presented to the map does not influence the final output (Kohonen, 2013). The SOM implementation provides a patent map that returns the technological clusters in which inventive efforts in EE are grouped. The patent map is run using eight-digit CPC codes assigned to each patent as input data. This patent classification system assigns codes to patent documents according to their technological content based on a hierarchical, languageindependent classification system. Thus, it defines the technological characteristics of the inventions in a standardised way that allows comparison between patents. Thanks to these features, CPC codes can be used to measure similarity between the technological content of patents, i.e. the strength of their technological relatedness (Scherer, 1982; Jaffe, 1986; Verspagen, 1997, among others). In the related literature, many efforts have been made to measure the technological relatedness between patents. For instance, Leydesdorff et al. (2014) built a matrix for measuring the number of times a patent 
Fig. 4 Trend of the radicalness index over time

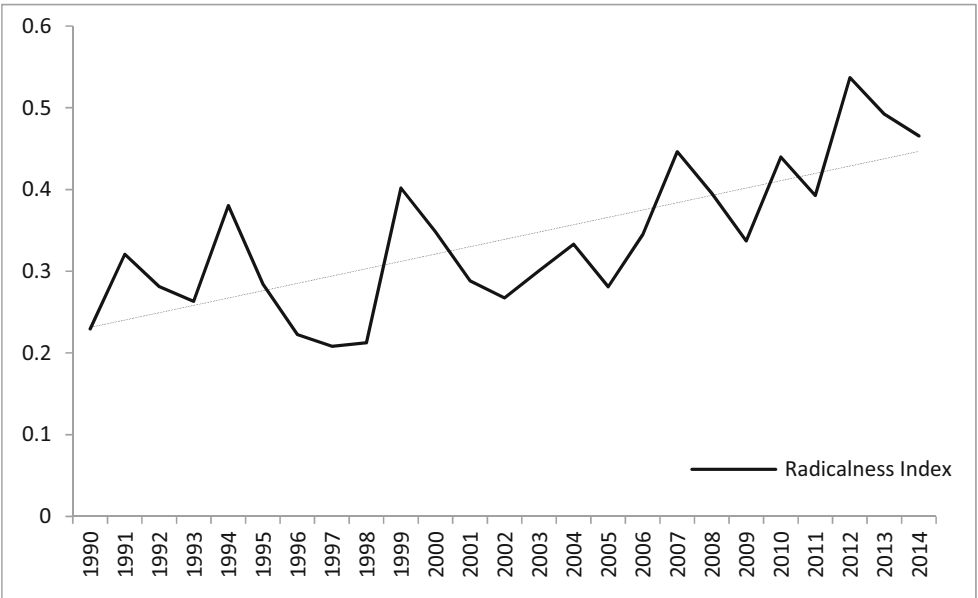

technological class is cited by other classes, using the cosine index as a measure of similarity. Breschi et al. (2003) and Nesta and Saviotti (2005), after describing each patent through a set of technological classes, used a matrix of co-occurrences to measure the strength between technological fields. Accordingly, we use co-occurrences of CPC codes assigned to each patent to define the technological similarity between them. We assume that the higher the number of shared CPC codes between two patents, the higher their technological similarity is. Therefore, the input data of the SOM is a matrix having, in each column, the frequency of eight-digit CPC classes assigned to each patent, with the univocal patent identification (publication number) in the rows. As a result, the SOM generates a patent map in which patents with similar (different) technological content are placed closer (distant).

Once the SOM has been trained, a visualisation process is required in order to show the resulting output. More precisely, the process consists of a method for locating the best matching units in an effective and visually attractive map (projection). Among different techniques (Vesanto, 1999), the unified distance matrix (U-Matrix) is proposed here, choosing a grid with a hexagonal lattice ${ }^{15}$ (Ultsch and Siemon, 1990). By assigning different colour hues according to the distance between each map node and its neighbour nodes, distance matrices show the similarity level between SOM nodes.

The main limitations in implementing the SOM algorithm relates to the time and computational

\footnotetext{
${ }^{15}$ The choice of the lattice only reflects aesthetical reasons since it does not produce bias in the data representation.
}

requirements needed to run the algorithm. Indeed, the algorithm is rather heavy computationally. Even if this problem affects most of the clustering techniques, the computational performances required by the SOM algorithm increase with the dimension of the map and input data. In addition, the SOM does not allow missing data for one or more dimensions of the input data. Even though this problem does not affect the present study, it may be the case in which it is impossible to acquire all the data to build the dataset. Lastly, Rauber et al. (2002) observed that conventional SOMs are not suitable to identify hierarchical relations between input data.

Based on the spatial order of input data, obtained using the SOM, map nodes are clustered through the non-hierarchical K-means algorithm (MacQueen 1967). By applying the K-means method, the nodes are partitioned into $k$ groups and clustered according to the method of centroids, i.e. points with a low distance between them and the other elements in the cluster. The number of clusters is defined by choosing $k$ based on the sum of squared errors. Finally, the Davis-Bouldin index (Davies and Bouldin, 1979) is calculated for each $k$, a clustering performance index that measures compactness and separation between nodes and clusters. The synergy that arises from the use of this two-stage method, i.e. SOM and clustering, produces more powerful results than using them singularly (Chi and Yang, 2008; Kuo et al., 2002).

By exploiting the topology-preserving feature of SOMs and their geometrical properties (preservation of the initial degree of CPC relatedness projected in a Euclidean space), we calculated two additional measures within the maps: the average distance between 
Fig. 5 U-matrix and K-means clustering for freezer/refrigerators

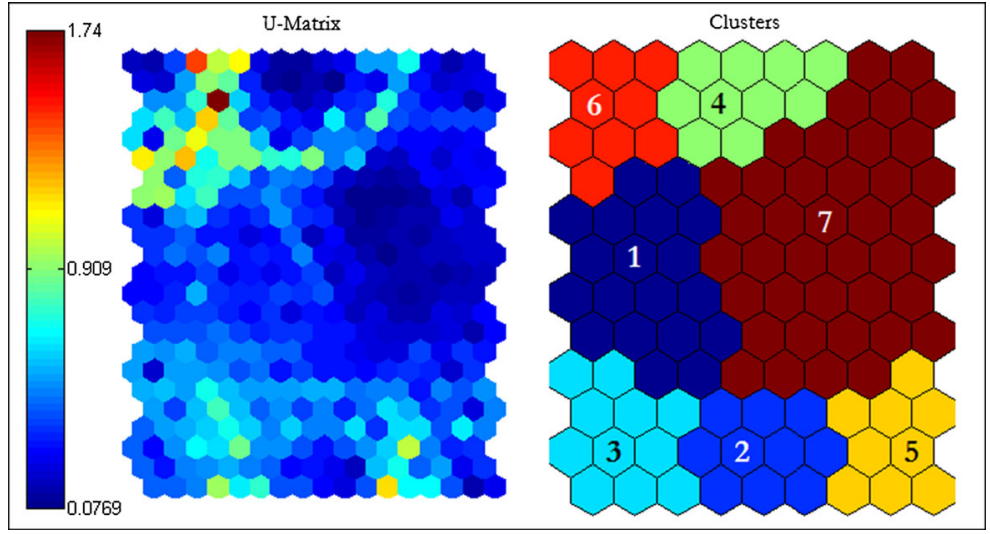

each cluster centroid (between distance) and the average distance between the nodes included in each cluster (within distance) ${ }^{16}$. The between distance is here used as a proxy for measuring the degree of spatial agglomeration captured by the cluster map. It is calculated for each cluster using the average Euclidean distance that separates the specific cluster centroid from all the other clusters' centroids. Accordingly, lower average distances imply a denser technology space since clusters' centroids agglomerate closer to others. On the contrary, higher average distance between clusters indicates that the cluster is located far away in the clustering space with respect to the others. On the other hand, the within distance is calculated using the average Euclidean distance between each SOM node within each cluster and captures the spatial density inside each cluster.

\section{Results and discussion}

Characteristics of the patenting activities in EE home appliances

Before exploring the technology space of each appliance, we provide some insights on the main characteristics of patenting activities in energy-efficient home appliances. We exploited information on the set of patents filed at the European Patent Office included in our original dataset. In so doing, although the number of observations on which the analysis is based does not

\footnotetext{
${ }^{16}$ Whereas the within distance is calculated using the average Euclidean distance between each node within each cluster, the 'between' distance is the average Euclidean distance between cluster centroids. Here, the centroid is measured using the geometric centre of the cluster nodes.
}

decrease (each triadic patent family includes a patent filed at the European Patent Office), we enhance the comparability and reliability of results. The motivation for this choice resides in the fact that each patent office follows its own rules, regulations and patenting strategies, and thus the international comparability of patent documents may be affected by this heterogeneity. In particular, the inclusion of citations in patents may differ across patent offices (Michel and Bettels, 2001). For instance, whereas citations at the US Patent and Trademark Office are shared by patent applicants, the European Patent Office only includes citations by patent examiners.

Figure 3 shows the evolution of the technology space in terms of CPC codes. It can be observed that the number of CPC codes included in our set of patent families increases over time (black line) ${ }^{17}$. This index can be used as a proxy for complexity of the knowledge space which grows in particular from 2007 onwards. This evidence suggests that the community of technologists increasingly explored different technological fields in order to overcome the hurdles which characterise energy consumption in domestic appliances. This evidence is supported by the second grey line of Fig. 3, which represents the number of CPC codes entering the technology space for the first time. These technological fields have never been explored before as far as the technologies under investigation are concerned. It can be noticed that at the beginning of the 1990s, the number of new, explored, CPC codes decreased over time with some fluctuations. However, from 2007 onwards, this index follows the trend in the

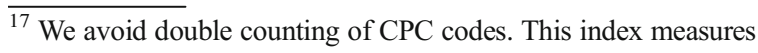
the number of CPC codes explored in 1 year.
} 
Table 3 Cluster identification for freezers/refrigerators

Refrigerators and freezers

Cluster no. Technology description

No. 7 Mechanical and electrical components (compressors, pumps etc.)

No. 3 Refrigerant circulation systems

No. 5 Components for power and control management

No. 1 New refrigerators and freezers (as a whole)

No. 4 Heat transfer and refrigerant compositions

No. 2 Insulation panels and foams

No. 6 Lubricant oils

Total

Mean 0.76
$\%$ patent share Average node distance Average distance per cluster within the cluster between CLs

$\begin{array}{lll}43.15(1) & 0.32(1) & 0.53(1) \\ 12.27(2) & 0.51(6) & 0.82(6) \\ 12.07(3) & 0.42(3) & 0.77(5) \\ 11.45(4) & 0.43(4) & 0.55(2) \\ 8.18(5) & 0.35(2) & 0.71(4) \\ 6.54(6) & 0.44(5) & 0.647(3) \\ 6.34(7) & 0.74(7) & 1.26(7)\end{array}$

100

Mean 0.46

Note: Cluster numbers are provided in the first column. The last two columns refer to average node distance within each cluster and average distance between clusters (for further details see the "SOM implementation" section). For the average node distance within each cluster, we tested the null hypothesis of equality between the mean node distance within each cluster and the mean node distance in the whole map. The null hypothesis has been rejected at the $99 \%$ level of confidence for each cluster

number of CPC included in patents. In particular, it rises from 2007, highlighting that the increase in complexity of the technology space is mainly driven by new technological fields never explored before. These issues shed light on the presence of an explorative phase, in which new technological fields are being explored as far as the technologies advance. Further interesting evidence derives from the analysis of patent quality. In this respect, Squicciarini et al. (2013) provided a set of indicators to measure different aspects of technological trends using patent data. We employ the Radicalness Index, proposed by Shane (2001), to measure the number of classification codes assigned to patents cited by a given patent. The value added of this index is that it takes into accounts only classification codes that are not included in the patent under analysis. For instance, if $\mathrm{CPC}$ codes $\mathrm{A}$ and $\mathrm{B}$ are assigned to patent 1 and $\mathrm{B}$ and $\mathrm{C}$ to patent 2, the radicalness index for patent 2 (patent 2 cites patent 1) does not provide information on the classification code B because it is included in both patents. Instead, it takes into account the CPC code A assigned only to the cited patent. The index is calculated as follows:

Radicalness Index $=\sum_{j}^{n_{p}} \frac{C T_{j}}{n_{p}} ; \mathrm{IPC}_{p j} \neq \mathrm{IPC}_{p}$.

where $C T_{j}$ refers to the number of International Patent Classification codes at four-digit $\mathrm{IPC}_{p j}$ of
Fig. 6 U-matrix and K-means clustering for washing machines

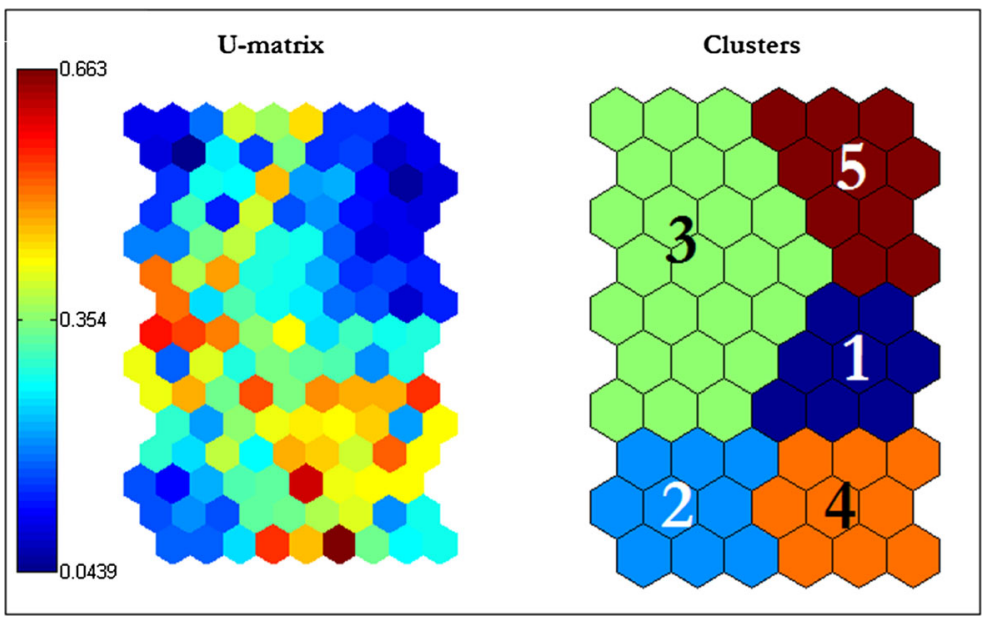


Fig. 7 U-matrix and K-means clustering for dishwashers

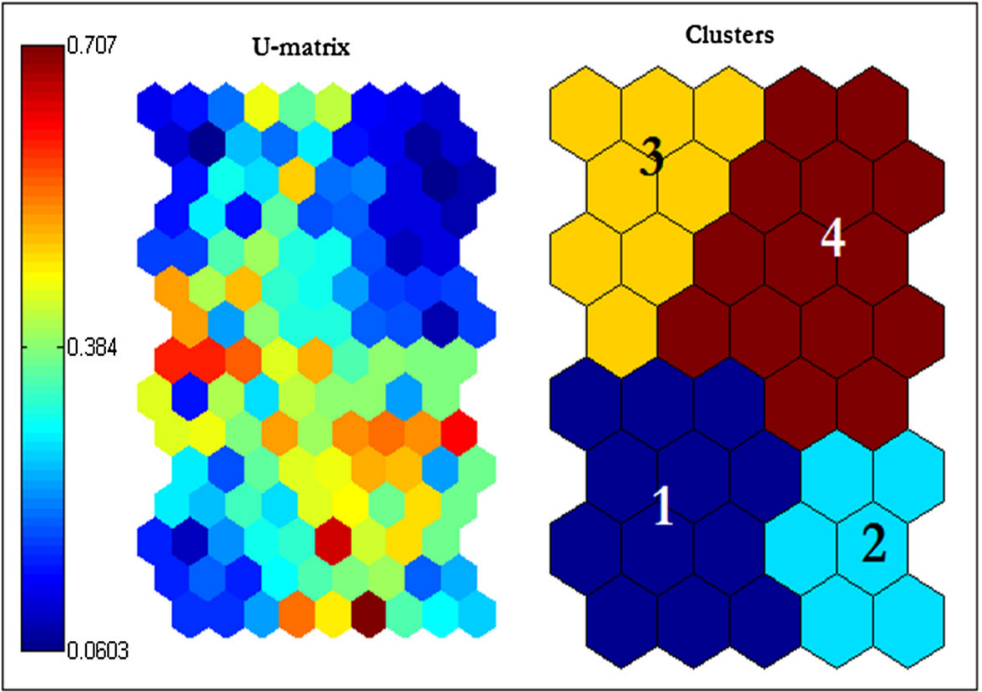

patent $j$ cited by patent $p$ that are not assigned to patent $p . n$ indicates the number of International Patent Classification codes in the cited patents calculated at the fifth hierarchical level.

High values of the radicalness index correspond to greater diversification of the knowledge base upon which the scrutinised patents build on. As we can observe from Fig. 4 the trend in the radicalness index is positive. This result confirms that, over time, technological advances in energy-efficient home appliances are characterised by heterogeneous prior art and increased complexity. It also provides evidence on the presence of an explorative phase in which different bits of knowledge (not necessarily strictly peculiar to the technologies analysed) are being combined to develop technologies with implications in terms of EE (Krafft et al., 2011).
Experiment I-identification of EE niches

In this first experiment, we use the entire patent sample to discover which technical components are related to EE improvements. These components are presented on the maps as clusters which include nodes with similar technological content, previously identified by the SOM. We repeat this experiment for each of the three groups of appliances, providing a clear picture of the pervasive nesting of EE in different appliance components such as mechanical, electro-mechanical, digital and chemical ones as well as in operational processes. The resulting framework is thus characterised by high technological complexity, generated by numerous clusters referring to a wide array of scientific and industrial contributions.

Table 4 Cluster identification for washing machines

Washing machines

\begin{tabular}{lllll}
\hline Cluster no. & Technology description & $\begin{array}{c}\text { \% patent share } \\
\text { per cluster }\end{array}$ & $\begin{array}{c}\text { Average node distance } \\
\text { within the cluster }\end{array}$ & $\begin{array}{c}\text { Average distance } \\
\text { between CLs }\end{array}$ \\
No. 3 & Mechanical and electromechanical components. & $47.37(1)$ & $0.38(2)$ & $0.67(2)$ \\
No. 5 & Washing process/methods and washing machine as a whole & $21.80(2)$ & $0.32(1)$ & $0.86(4)$ \\
No. 4 & Digital components for energy management & $12.03(3)$ & $0.45(3)$ & $0.95(5)$ \\
No. 2 & Sensors & $11.28(4)$ & $0.52(5)$ & $0.85(3)$ \\
No. 1 & Motion and heating electrical controllers. & $7.52(5)$ & $0.47(4)$ & $0.61(1)$ \\
Total & 100 & Mean 0.43 & Mean 0.79 &
\end{tabular}

Note: Cluster numbers are provided in the first column. The last two columns refer to average node distance within each cluster and average distance between clusters (for further details see the "SOM implementation" section). For the average node distance within each cluster, we tested the null hypothesis of equality between the mean node distance within each cluster and the mean node distance in the whole map. The null hypothesis has been rejected at the $99 \%$ level of confidence for each cluster 
Table 5 Cluster identification for dishwashers

Dishwashers

Cluster no. Technology description

No. 4 Other components (mechanical, electromechanical and chemical)

No. 3 New washing methods and dishwashers as a whole

No. 1 Components for energy management

No. 2 Controllers and sensors

Total

$\begin{array}{lll}\begin{array}{c}\text { \% patent share } \\ \text { per cluster }\end{array} & \begin{array}{c}\text { Average node distance } \\ \text { within the cluster }\end{array} & \begin{array}{c}\text { Average distance } \\ \text { between CLs }\end{array} \\ 40.91(1) & 0.35(2) & 0.59(1) \\ 24.24(2) & 0.35(1) & 0.76(3) \\ 22.73(3) & 0.53(4) & 0.71(2) \\ 12.12(4) & 0.44(3) & 0.79(4) \\ 100 & \text { Mean } 0.42 & \text { Mean } 0.71\end{array}$

Note: Cluster numbers are provided in the first column. The last two columns refer to average node distance within each cluster and average distance between clusters (for further details see the "SOM implementation" section). For the average node distance within each cluster, we tested the null hypothesis of equality between the mean node distance within each cluster and the mean node distance in the whole map. The null hypothesis has been rejected at the $99 \%$ level of confidence for each cluster

In the case of freezers/refrigerators, we identified seven clusters (Fig. 5). A first, generic cluster (no. 1) includes patents on new freezers/refrigerators as a whole; excluding this, the others constitute a set of specific technology clusters which decompose the technology space of the appliance under scrutiny. As shown in Table 3, clusters 7 , $3,5,4,2$ and 6 , belong to various technological fields, ranging from electrical components (i.e. energy management systems, which include sensors, microprocessors, displays and firmware) to chemical components (i.e. refrigerant compositions, insulating foams and lubricant oils).

The pervasiveness of EE appears, as in the previous case, also when we repeat the experiment in the set of washing appliances, i.e. washing machines and dishwashers, whose results are represented in Figs. 6 and 7, respectively. It is worth noting that, although the number of patents belonging to these two appliances is lower, EE still affects a variety of clusters. In particular, we identified 5 clusters (133 patents in total) for washing machines and
4 clusters (66 patents in total) for dishwashers shown in Tables 4 and 5, respectively. The identification of these clusters confirms the hypothesis on the presence of the resource-pooling effect also in these two electrical appliances. Indeed, the niches aimed at improving the level of EE pool a variety of different industries that produce technologies deriving from the application of several scientific fields. Moreover, since each cluster includes a different number of patents, we can also derive a measure of innovation effort in each specific technological cluster. In other words, it is possible to identify where most of the efforts for EE gains have been addressed within each single appliance over the entire period of analysis, specifying that such a rank only assumes a qualitative nature since an assessment of the technological patent value does not constitute the main objective of this work.

Further investigation is based on a spatial analysis of clusters. In the case of freezers/refrigerators, the core cluster is graphically represented by cluster 7 . This includes
Fig. 8 Percentage of triadic patents in freezers/refrigerators clusters over time

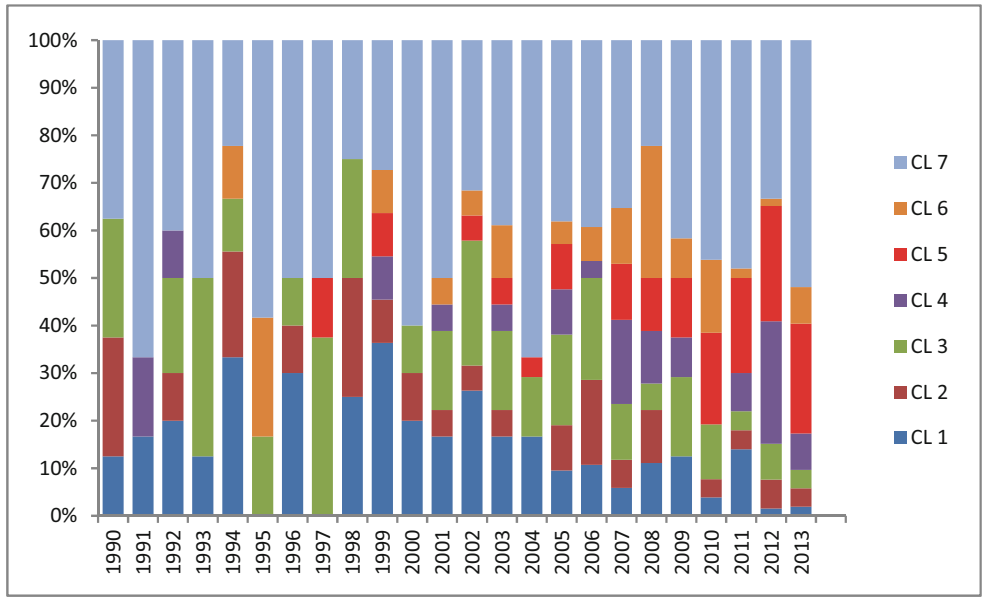




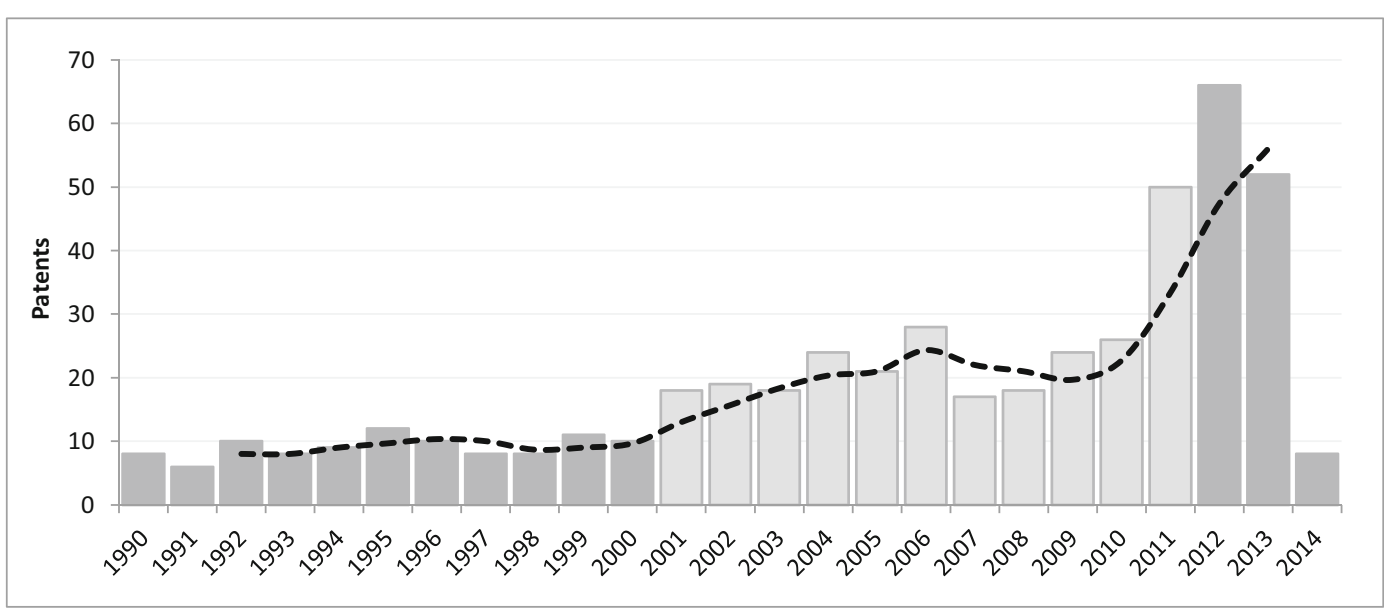

Fig. 9 Histogram of patent distribution for freezers/refrigerators (1990-2014) and 3-year moving average trend (dotted line)

the highest number of patents ( $43 \%$ of the sample) which are related to mechanical and electromechanical components. Such centrality is confirmed by comparing the between distances, which is the lowest among the clusters (0.53). The level of centrality approximates the degree of technology integration and combination. Thus, peripheral technologies (refrigerants, sensors, insulations panels) seem to be complementary and to serve the core technology (compressors, pumps and other mechanical components). The low within distances in cluster 7 (mechanical and electromechanical components) and cluster 4 (chemical compositions for heat transfer and refrigerant liquids) indicate more dense technological clusters characterised by a high technological specificity.

\section{Experiment II—comparison over time}

In the second experiment, we only take into account patents for cooling appliances (freezers/refrigerators) and divide the sample into two sub-samples by including the first and last 100 patents sorted by publication date. It is worth noting that the distribution of patenting activity across years is not homogenous since the first 100 patents are spread across 11 years (1990-2000), whereas the second 100 refer only to a 3-year period (2012-2014).

As shown in Fig. 8, we moved to a more complex framework of technology variety, which provides first evidence of growing technological complexity due to the different contents of clusters that increases over time, expressed as percentages. Figure 8 highlights the emergence of three main clusters from 2000 onwards, i.e. heat transfer and refrigerant compositions (cluster 4), components for power and control management (cluster
5) and lubricant oils (cluster 6$)^{18}$. By repeating experiment I for the two sub-samples, we produce two temporal sections of the domestic cooling appliances aimed at comparing technological advances in EE components. Figure 9 shows the histogram of the total distribution of freezers/refrigerators patents in the years covered by the two sub-samples (in dark grey). The number of new patents belonging to energy-efficient freezers and refrigerators is clearly skewed toward more recent years, signalling increasing innovative efforts made by manufacturers to provide their appliances with more and more EE improvements. When we look at the patent maps (Fig. 10), we note an equal number of clusters, but when the latter are under scrutiny, they unveil different technological content (Table 6).

Indeed, in the first period, the technology space is mainly characterised by mechanical and electromechanical components and more efficient appliances as a whole, which together constitute almost $93 \%$ of the total patent families in the period analysed. On the contrary, in more recent years, the massive presence of digital components for energy management and motion control can be observed together with an increasing share of patent families related to new compositions for refrigerants. According to Table 6, the analysis of the technology space between the frame 1990-1999 and 2012-2014 highlights the introduction of a new cluster (no. 2) whose content includes $19 \%$ of the total patent families, all related to 'components for

\footnotetext{
${ }^{18}$ We dropped 2014 from Fig. 8 in which only three clusters were reported. The results for that year would be biased given the low number of patent families in that year (as shown in Fig. 9), mainly due to the time needed to disclose the invention, file and publish patent applications.
} 
Fig. 10 Comparison of EE technology clusters for freezers/ refrigerators in two different periods (1990-1999 and 20122014).
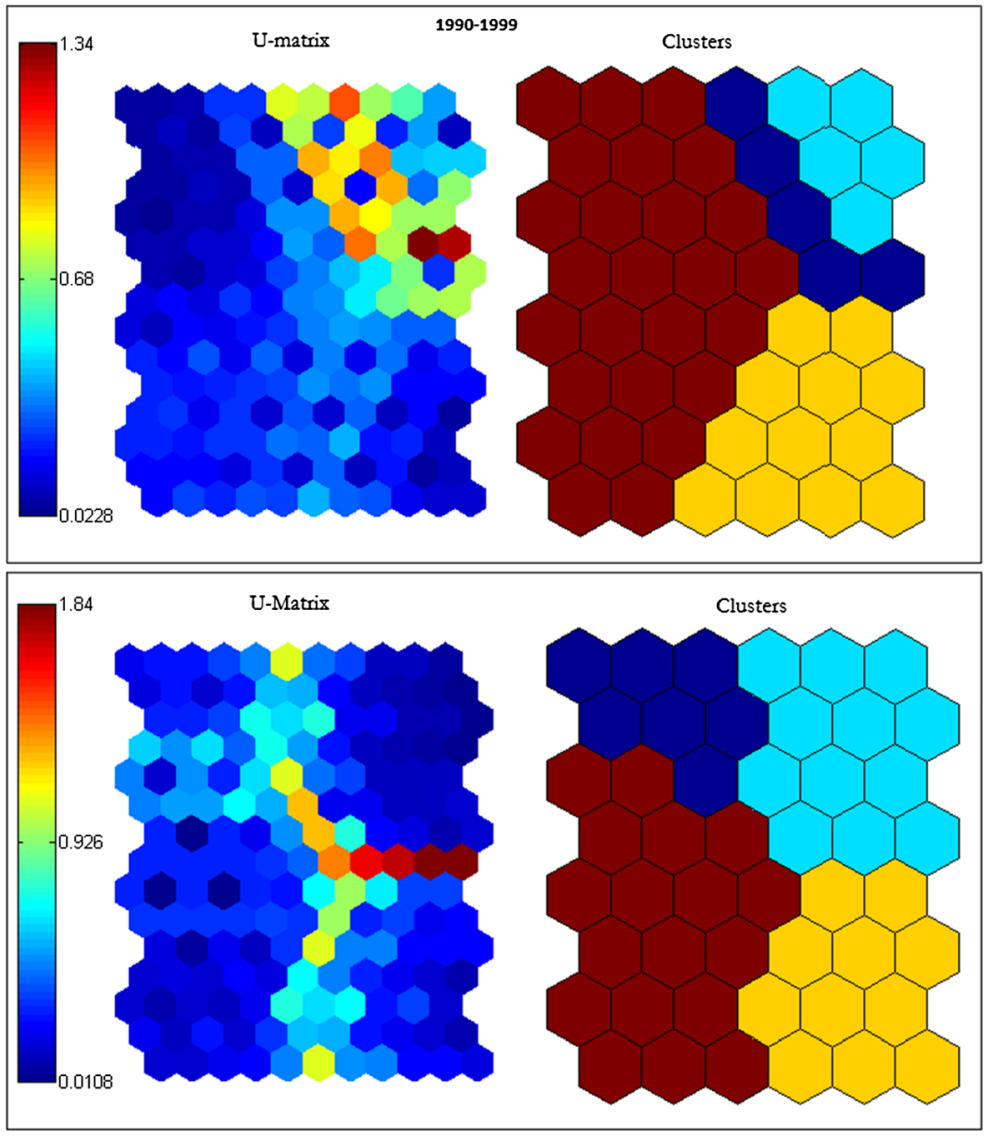

power supply management'. The average within distance of this cluster is 0.20 , depicting a very dense space characterised by digital devices and components enabling a more efficient operation of freezers and refrigerators. Although the presence of mechanical components (cluster 4 of Table 6) still dominates the technology space, this latter is characterised by a more complex structure which gives rise to higher technological recombination ${ }^{19}$ and accrues the resource-pooling effect. The result of this part of analysis provides a clear picture on how the technology space for domestic EE technologies evolved, showing a dematerialisation process from mechanical to digital components and most likely improving the level of EE jointly operating by relying on different technological contributions. In addition, as far as the within and between distance are concerned, we can observe that a decrease in

\footnotetext{
$\overline{19}$ According to Antonelli (1999), the technological recombination can operate both vertically (diachronic recombination) and horizontally (synchronic recombination). The first refers to a recombination of past elements of knowledge, while the second exploits contemporary acquisition of new pieces of knowledge (Antonelli, 1999).
}

both the measures provides an insight into the growing density in the technology space across time, although the number of clusters remains the same.

\section{Experiment III—-technological fungibility}

The third experiment investigates the presence of technological fungibility between two different groups of appliances by analysing the joint-use relationships of their EE technological components. We used co-occurrence analysis of CPC classes to identify multi-appliance patent families, i.e. patents related to more than one appliance. This experiment focuses on patent families with technological advances both in (i) freezers/refrigerators and washing machines and (ii) washing machines and dishwashers. We exploited the results of experiment I for keeping information, in the SOM outputs, on each patent within nodes and clusters. It was thus possible to detect not only multiappliance patents (i.e. patents employed in different appliances) but also the technological clusters to which those patents refer to. As a further step, the percentage of multi- 


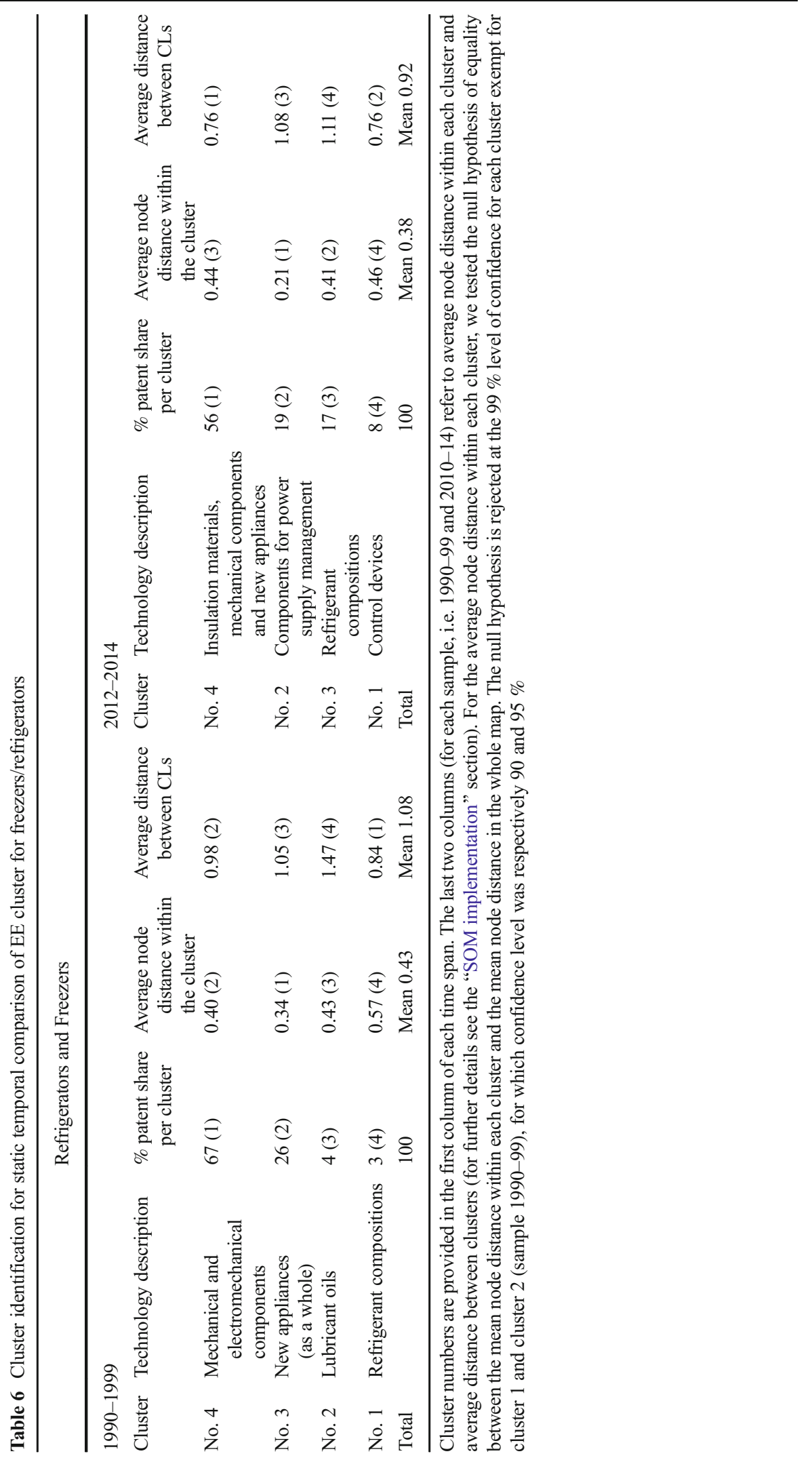


Fig. 11 Technological fungibility of EE components between freezers/refrigerators and washing machines

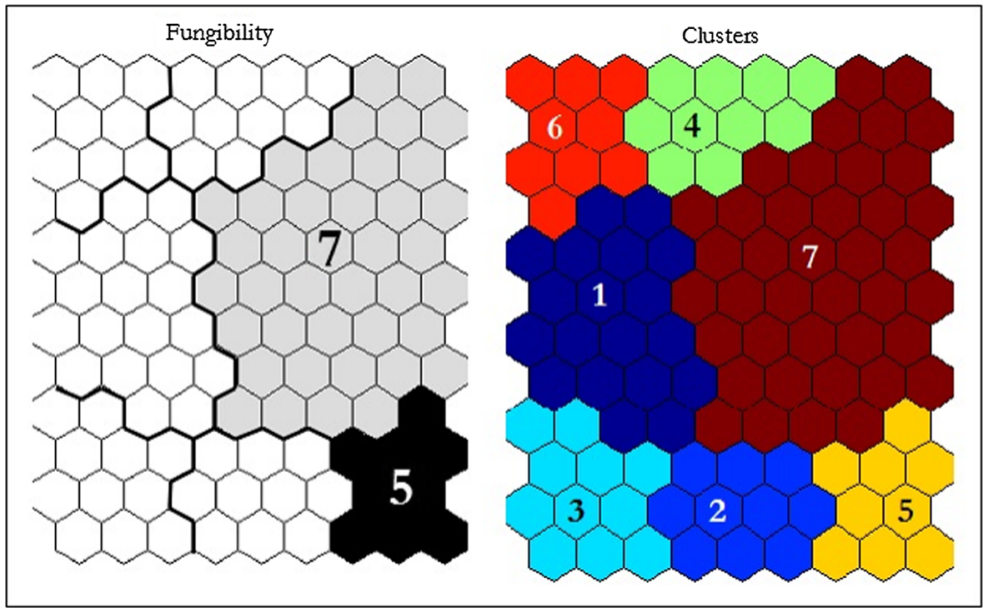

appliance patent families was calculated for each cluster. Lastly, we used the SOM outputs of experiment I to produce maps with a black-white visualisation scheme in which the percentage of black is proportional to the percentage of multi-appliance patents found in each cluster. The results in Figs. 11 and 12 clearly show in which clusters technological fungibility of $\mathrm{EE}$ components is nested. Specifically, both in the case of freezers/ refrigerator vs. washing machines, as well as in the case of washing machines vs. dishwashers, the cluster containing digital components for energy management and motion control (no. 5 and no. 4, for freezers/refrigerators and washing machines, respectively) has been identified as the most pervasive and containing the highest level of fungible components.

In our case, power management and control systems include digital and communication devices as well as firmware and microprocessors that can be employed in a

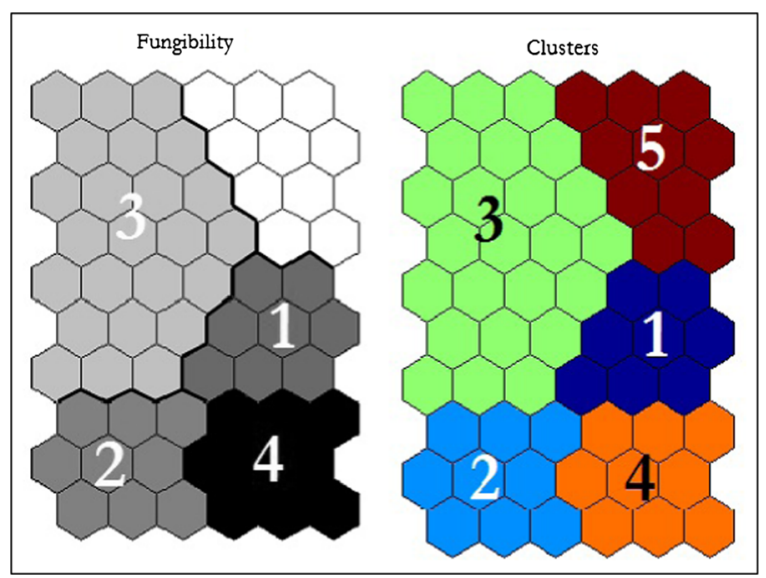

Fig. 12 Technological fungibility of EE components between washing machines and dishwashers wide range of applications (general applicability) and characterised by continuous improvements (technological dynamism) considering the enormous growth of ICTs which has occurred recently (Cecere et al. 2014). In these dynamics, EE accommodates well and strongly exploits the interchangeable technology space of domestic electrical appliances.

\section{Conclusions}

The present work uses an original patent dataset belonging to three groups of energy-efficient domestic appliances (i.e. freezers/refrigerators, washing machines and dishwashers) to develop, using SOMs, an analysis model in order to test a series of theoretical hypotheses. These hypotheses refer to (i) the pervasiveness of EE in different technological components, (ii) the presence of a resourcepooling effect as a result of growing technological variety and development and (iii) the fungibility of EE technological components in different appliances.

In the first experiment, we find the technology clusters in which EE is nested. This experiment is thus repeated for each of the three groups of appliances, providing a clear picture of the pervasive nesting of EE in different appliance components such as mechanical, electro-mechanical, digital and chemical ones as well as in operational processes. Our results confirm that EE is affected by pervasiveness and tends to be nested in many different technological fields, thus admitting hypothesis (i). By also comparing the number of inventions belonging to each cluster, we derived a measure of innovation effort in each specific technological field, 
making it possible to identify where most of the efforts for EE gains are addressed in each single appliance. Considering the entire sample of patent families, dating from 1990 to 2014, such innovative efforts seem to be concentrated in mechanical and electrical components, without exceptions among the three groups of appliances.

In the second experiment, we compared the technology space between two different periods, finding higher levels of complexity along with a strong presence of the resource-pooling effect due to the growing technological variety. Technology space dynamics show a dematerialisation process initially characterised by the almost exclusive presence of mechanical components and, over time, moving toward an increasing complexity dominated by a growing presence of digital components of a different nature.

Our third experiment is devoted to investigating the hypothesis of technological fungibility, finding that technology clusters containing patent families pertaining to different appliances were particularly evident between two different couples of appliances, namely between freezers/refrigerators and washing machines and between washing machines and dishwashers. As a result, in both cases, we identified a single cluster that includes patents for energy management and digital motion control. This technological cluster, characterised by the highest level of fungible components and rapid growth, can be referred to the group of ICTs, defined by many authors as a general purpose technology, that is, a technology showing general applicability, technological dynamism and able to generate lower reproducibility costs for manufacturers. In light of this, we conclude that this technological cluster, including the set of components referring to power management and digital motion controllers, appears not only particularly able to embrace the aim of EE, but it also constitutes an interesting case of technological fungibility when domestic electrical appliances are under scrutiny.

The results obtained across the three experiments allow us to derive some useful implications for policy makers and stakeholders. First, although the set of white goods analysed constitute mature technologies, the literature suggests that significant EE improvements were obtained in the last 20 years, with associated energy reduction. Even though the identification of the causal link between policy implementation and saving impacts goes beyond the scope of our analysis, we point out that the complex instrument mix of environmental, innovation and energy policies have had a role in shaping the rate and pattern of the technology space here analysed. In this respect, our research identifies the technology clusters and their dynamics through which these EE improvements took place, signalling the relevant role of information-technology devices such as the integration with microprocessors, digital sensors, fuzzy operational approaches, digital displays and more complex firmware, which are more and more integrated in the electrical appliances. Since these components are characterised by a high fungibility (a more general applicability to different appliances, e.g. a firmware for a fridge can be easily re-programmed and employed in a dishwasher), R\&D incentives and other supply-push innovation policies matter in the portfolio of EE policies. These latter should go hand in hand with the inventive performance of appliance manufacturers. Second, given the growing resource-pooling effect characterising modern traditional appliances, incentives should also be targeted toward firms characterised by horizontally integrated industries and industrial partnerships, a characteristic often found in multinational appliance manufacturers. For the same reason, the characteristic of being vertically integrating at industrial level should also favour firms to save costs. Third, it is worth considering that modern white goods are able to 'communicate' with end-users much more than in the past, thanks to the increasing integration of displays and operating options deriving from the ICT sector. These new appliance features provide consumers with useful consumption and operation feedbacks. In light of this, there is room for further demand-pull EE policies aimed at promoting appliances characterised by higher interactivity and control options, combined with a more active role of technicians and sellers suggesting these product categories. This would increase the pace at which policies aimed at replacing older energy-intensive appliances with new ones operate (Hyung et al., 2006), which represents an effective policy tool to reduce the electricity consumption if we consider that the efficiency performance of household appliances deteriorates over time.

Acknowledgments We acknowledge financial support from the Italian Ministry of Education, University and Research (Scientific Research Programme of National Relevance 2010 on 'Climate change in the Mediterranean area: scenarios, economic impacts, mitigation policies and technological innovation'). We are also grateful to Davide Consoli, Valeria Costantini and Nicoletta Corrocher for their precious comments and suggestions. The usual disclaimer applies. 


\section{Appendix}

Table 7 List of CPC-Y02B 40 classes and related descriptions

Y02B 40 - technologies aiming at improving the efficiency of home appliances

\begin{tabular}{|c|c|}
\hline \multirow[t]{3}{*}{ Y02B 40/30 } & $\begin{array}{l}\text { Relating to refrigerators } \\
\text { or freezers }\end{array}$ \\
\hline & Y02B 40/32 \\
\hline & Y02B 40/34 \\
\hline \multirow[t]{3}{*}{ Y02B 40/40 } & $\begin{array}{l}\text { Relating to } \\
\text { dish-washers }\end{array}$ \\
\hline & Y02B 40/42 \\
\hline & Y02B 40/44 \\
\hline \multirow[t]{5}{*}{ Y02B 40/50 } & $\begin{array}{l}\text { Relating to } \\
\text { washing machines }\end{array}$ \\
\hline & Y02B 40/52 \\
\hline & Y02B 40/54 \\
\hline & Y02B 40/56 \\
\hline & Y02B 40/58 \\
\hline
\end{tabular}

Table 8 List of search strings

\begin{tabular}{llc}
\hline Electrical appliance & First-level keywords & Second-level keywords \\
\hline Freezers and refrigerators & energysav* OR energy efficien* OR energy conservation & refrigerator OR refrigerators \\
& OR high efficien* OR low energy OR low-energy & OR fridge OR fridges \\
Washing machines & OR low electricity consumption OR energy reduction & washingmachine* \\
Dishwashers & OR energy economis* OR energy economiz* OR energy & dishwash* \\
& performanc* OR less electric energy OR less electricity & \\
& OR less energy OR energy use manage OR energy ADJ & \\
& use control* OR energy manage*) AND (residen* OR hous* & \\
& OR domestic OR hom* OR dwellin* OR famil*) & \\
\hline
\end{tabular}


Table 9 List of clusters and associated content of patent families

\begin{tabular}{|c|c|c|}
\hline Appliance & Cluster & Description \\
\hline \multirow[t]{4}{*}{ Dishwasher } & CL1 & $\begin{array}{l}\text { Energy management systems, communication devices, methods and systems for managing energy supply, } \\
\text { demand and usage }\end{array}$ \\
\hline & CL2 & Methods and apparatus for monitoring and measuring energy usage \\
\hline & CL3 & Improvement in the appliance as a whole and methods, such as drying, rinsing and sorption methods, etc. \\
\hline & CL4 & Components such as water storage tanks, thermal insulation materials, etc. \\
\hline \multirow{7}{*}{$\begin{array}{l}\text { Freezers and } \\
\quad \text { refrigerators }\end{array}$} & CL1 & Freezer and refrigerator devices and apparatus. New appliance design and architecture \\
\hline & CL2 & Thermal insulator devices, refrigerator cabinets and insulating boxes, vacuum heat insulator material \\
\hline & CL3 & $\begin{array}{l}\text { Refrigeration circuit including compressors, method and apparatus for the sensing of refrigerant temperatures } \\
\text { and control of refrigerant loading }\end{array}$ \\
\hline & CL4 & Composition comprising tetrafluoropropene and difluoromethane or other components \\
\hline & CL5 & Power supply/demand control systems, energy management systems. \\
\hline & CL6 & Lubricant oil compositions \\
\hline & CL7 & Devices and apparatus such as electric power systems, lighting apparatus, compressors, electric motors, etc. \\
\hline \multirow[t]{5}{*}{ Washing machine } & CL1 & Power supply and demand control system, power supply systems, voltage controls \\
\hline & CL2 & Monitoring apparatus to control energy consumption \\
\hline & CL3 & Mechanical and electromechanical components such as electric motor, inverters, stators, etc. \\
\hline & CL4 & Energy management system which can increase the awareness of energy saving \\
\hline & CL5 & Washing machine design as a whole \\
\hline
\end{tabular}

\section{References}

Abbas, A., Zhang, L., \& Khan, S. U. (2014). A literature review on the state-of-the-art in patent analysis. World Patent Information, 37, 3-13.

Antonelli, C. (1992a). The economics of information networks (Ed). Amsterdam: Elsevier.

Antonelli, C. (Ed.) (1992b). The economics of information networks. Amsterdam: Elsevier.

Antonelli, C. (1999). The microdynamics of technological change. London: Routledge.

Antonelli, C. (2003). Knowledge complementarity and fungibility: implications for regional strategy. Regional Studies, 37(6-7), 595-606.

Archibugi, D., \& Pianta, M. (1996). Measuring technological change through patents and innovation surveys. Technovation, 16(9), 451-468.

Arundel, A., \& Kabla, W. E. (1998). What percentage of innovations are patented? Empirical estimates for European firms. Research Policy, 27(2), 127-141.

Atanasiu, B., \& Bertoldi, P. (2008). Residential electricity consumption in new member states and candidate countries. Energy and Buildings, 40(2), 112-125.

Barberá-Tomás, D., \& Consoli, D. (2012). Whatever works: uncertainty and technological hybrids in medical innovation.
Technological Forecasting and Social Change, 79(5), 932948.

Barbieri, N. (2015). Investigating the impacts of technological position and European environmental regulation on green automotive patent activity. Ecological Economics, 117, $140-152$.

Bertoldi P., Atanasiu B. (2007). Electricity consumption and efficiency trends in the enlarged European Union-status report 2006-EUR 22753EN. Institute for Environment and Sustainability, JRC European Commission.

Borg, S. P., \& Kelly, N. J. (2011). The effect of appliance energy efficiency improvements on domestic electric loads in European households. Energy and Buildings, 43, 22402250 .

Breschi S., Lissoni F., Malerba F. (2003). Knowledge-relatedness in firm technological diversification. Research Policy, 32(1), pp. 69-87.

Bresnahan TF. (2010). General purpose technologies, in: Hall B., Rosenberg N. (eds.) Handbook of the Economics of Innovation 2, North Holland, 2010, pp. 761-791.

Bresnahan, T. F., \& Traitenberg, M. (1995). General purpose technologies: 'engines of growth'? Journal of Econometrics, 65, 83-108.

Burwell, C. C., \& Sweezey, B. G. (1990). The home: evolving technologies for satisfying human wants. In S. H. Schurr, C. C. Burwell, W. D. Devine, \& S. Sonenblum (Eds.), 
Electricity in the American economy: agent of technological progress. New York: Greenwood Press.

Campanario, J. M. (1995). Using neural networks to study networks of scientific journals. Scientometrics, 33(1), 23-40.

Carlei, V., \& Nuccio, M. (2014). Mapping industrial patterns in spatial agglomeration: a SOM approach to Italian industrial districts. Pattern Recognition Letters, 40(1), 1-10.

Cecere, G., Corrocher, N., Gossart, C., \& Ozman, M. (2014). Technological pervasiveness and variety of innovators in green ICT: a patent-based analysis. Research Policy, 43(10), 1827-1839.

Chi, S. C., \& Yang, C. C. (2008). A two-stage clustering method combining ant colony SOM and K-means. Journal of Information Science \& Engineering, 24(5), 1445-1460.

Corrocher, N., Malerba, F., \& Montobbio, F. (2007). Schumpeterian patterns of innovative activity in the ICT field. Research Policy, 36(3), 418-432.

Costantini, V., Crespi, F., \& Curci, Y. (2013). BioPat: an investigation tool for analysis of industry evolution, technological paths and policy impact in the biofuels sector. In V. Costantini \& M. Mazzanti (Eds.), The dynamics of environmental and economic systems. Innovation, environmental policy and competitiveness. Netherlands: Springer.

Costantini V., Crespi, F., Palma, A. (2014), Mapping innovation systems through patent analysis. The case of technologies for energy efficiency in the residential sector, in Patrucco P. (Ed.) The Economics of Knowledge Generation and Distribution: The Role of Interactions in the System Dynamics of Innovation and Growth, Routledge.

Datta, S., \& Gulati, S. (2014). Utility rebates for ENERGY STAR appliances: are they effective? Journal of Environmental Economics and Management, 68(3), 480-506.

Davies, D. L., \& Bouldin, D. W. (1979). A cluster separation measure. IEEE Transactions on Pattern Analysis and Machine Intelligence, 1, 224-227.

Dernis, H. and M. Khan (2004). Triadic patent families methodology. OECD Science, Technology and Industry Working Papers, 2004/02, OECD Publishing.

EC (2011). Communication from the Commission to the European parliament. Energy Efficiency Plan 2011.Com. (2011) 109.Technical report, European Commission.

EC-JTR (2012). Energy efficiency status report 2012. Electricity consumption and efficiency trends in the EU-27. Joint Research Center Scientific and Policy Reports.

Epicoco, M. (2013). Knowledge patterns and sources of leadership: mapping the semiconductor miniaturization trajectory. Research Policy, 42(1), 180-195.

Filippini, M., Hunt, L. C., \& Zorić, J. (2014). Impact of energy policy instruments on the estimated level of underlying energy efficiency in the EU residential sector. Energy Policy, 69(C), 73-81.

Florax R., De Groot H., Mulder P. (2011). Improving energy efficiency through technology: trends, investment behaviour and policy design. Edward Elgar Publishing, Inc.

Galarraga, I., González-Eguino, M., \& Markandya, A. (2011a). Willingness to pay and price elasticities of demand for energy-efficient appliances: combining the hedonic approach and demand systems. Energy Economics, 33, 66-74.

Galarraga, I., Heres, D., \& González-Eguino, M. (2011b). Price premium for high-efficiency refrigerators and calculation of price-elasticities for close-substitutes: combining hedonic pricing and demand systems. Journal of Cleaner Production, 19, 2075-2081.

Galarraga, I., Abadie Luis, I., \& Kallbekken, S. (2016). Designing incentive schemes for promoting energy-efficient appliances: a new methodology and a case study for Spain. Energy Policy, 90, 24-36.

Gillingham, K., Newell, R., \& Palmer, K. (2009). Energy efficiency economics and policy. Annual Review of Resource Economics, 2(1), 597-620.

Giudici, P. (2003). Applied data mining. Statistical methods for business and industry. The Atrium, Southern Gate, Chichester, England: John Wiley \& Sons Ltd.

Griliches, Z.(1990). Patent Statistics as Economic Indicators: A Survey. Journal of Economic Literature, American Economic Association, 28(4), 1661-1707.

Griliches Z. (1998). Patent statistics as economic indicators: a survey. In R\&D and Productivity: The Econometric Evidence. Ed. Zvi Griliches. National Bureau of Economic Research. University of Chicago Press.

Hall, B. H., Jaffe, A., \& Trajtenberg, M. (2005). Market value and patent citations. RAND Journal of Economics, 36(1), 16-38.

Huang, Z., Chen, H., Chen, Z.-H., \& Roco, M. C. (2004). International nanotechnology development in 2003: country, institution, and technology field analysis based on USPTO patent database. Journal of Nanoparticle Research, 6, 325354.

Hyung, C. K., Keoleian, G. A., \& Horie, Y. A. (2006). Optimal household refrigerator replacement policy for life cycle energy, greenhouse gas emissions, and cost. Energy Policy, 34(15), 2310-2323.

IEA (2009). Gadgets and gigawatts. Policies for energy efficient electronics. OECD/International Energy Agency.

IEA (2012). Energy technology perspectives 2012: pathways to a clean energy system. OECD/International Energy Agency.

Jaffe, A. (1986). Technological opportunity and spillovers of R\&D. American Economic Review, 76, 984-1001.

Jaffe, A., \& Trajtenberg, M. (2004). Patents, citations, and innovations: a window on the knowledge economy. Journal of Economic Literature, 42(4), 1158-1160.

Kim, Y. G., Suh, J. H., \& Park, S. C. (2008). Visualization of patent analysis for emerging technology. Expert Systems with Applications, 34(3), 1804-1812.

Kohonen, T. (1990). The self-organizing map. Proceedings of the IEEE, 78(9), 1464-1480.

Kohonen, T. (1998). The self-organizing map. Neurocomputing, 21(1), 1-6.

Kohonen, T. (2001). Self-organizing maps (Vol. 30). Springer Science \& Business Media.

Kohonen, T. (2013). Essentials of the self-organizing map. Neural Networks, 37, 52-65.

Kohonen, T., Oja, E., Simula, O., Visa, A., \& Kangas, J. (1996). Engineering applications of the self-organizing map. Proceedings of the IEEE, 84(10), 1358-1384.

Koomey, J. G. (2007). Estimating total power consumption by servers in the US and the world.

Krafft, J., Quatraro, F., \& Saviotti, P. P. (2011). The knowledgebase evolution in biotechnology: a social network analysis. Economics of Innovation and New Technology, 20(5), 445475.

Kuo, R. J., Ho, L. M., \& Hu, C. M. (2002). Integration of selforganizing feature map and K-means algorithm for market 
segmentation. Computers \& Operations Research, 29-11, 1475-1493.

Lagus, K., Kaski, S., \& Kohonen, T. (2004). Mining massive document collections by the WEBSOM method. Information Sciences, 163(1), 135-156.

Lee S., Yoon B., Park Y. (2009). An approach to discovering new technology opportunities: keyword-based patent map approach. Technovation, Vol. 29 (6-7), pp. 481-497.

Leydesdorff, L., Kushnir, D., \& Rafols, W. E. (2014). Interactive overlay maps for US patent (USPTO) data based on international patent classification (IPC. Scientometrics, 98(3), 15831599.

MacQueen J. B. (1967). Some methods for classification and analysis of multivariate observations. In Proceedings of 5th Berkeley symposium on mathematical statistics and probability, pp. 281-297.

Martinez C. (2010). Insight into different types of patent families, OECD Science, Technology and Industry Working Papers, 2010/02, OECD Publishing.

Martiskainen, M., \& Coburn, J. (2011). The role of information and communication technologies (ICTs) in household energy consumption - prospects for the UK. Energy Efficiency, 4(2), 209-221.

McKinsey \& Company (2009). Pathways to a low-carbon economy: version 2 of the Global Greenhouse Gas Abatement Cost Curve.

Michel, J., \& Bettels, B. (2001). Patent citation analysis. A closer look at the basic input data from patent search reports. Scientometrics, 51(1), 185-201.

Narin F. (2000). Tech-Line ${ }^{\circledR}$ background Paper. In J. Tidd, Measuring Strategic Competence. London: Imperial College.

Nesta, L., \& Saviotti, P. P. (2005). Coherence of the knowledge base and the firm's innovative performance: evidence from the US pharmaceutical industry. The Journal of Industrial Economics, 53(1), 123-142.

Noailly, J., \& Batrakova, S. (2010). Stimulating energy-efficient innovations in the Dutch building sector: empirical evidence from patent counts and policy lessons. Energy Policy, 38, 7803-7817.

Panzar, J. C., \& Willig, R. D. (1981). Economies of scope. American Economic Review, 71(2), 268-272.

Park, H., Yoon, J., \& Kim, K. (2013). Identification and evaluation of corporations for merger and acquisition strategies using patent information and text mining. Scientometrics, 97(3), 883-909.

Patterson, M. G. (1996). What is energy efficiency? Concepts, indicators, methodological issues. Energy Policy, 24(5), 377390.

Peine, A. (2009). Understanding the dynamics of technological configurations: a conceptual framework and the case of smart homes. Technological Forecasting and Social Change, 76, 396-409.

Polanco, X., François, C., \& Lamirel, J. C. (2001). Using artificial neural networks for mapping of science and technology: a multi-self-organizing-maps approach. Scientometrics, 51(1), 267-292.

Popp, D. (2005). Lessons from patents: using patents to measure technological change in environmental models. Ecological Economics, 54(2), 209-226.

Rauber, A., Merkl, D., \& Dittenbach, M. (2002). The growing hierarchical self-organizing map: exploratory analysis of high-dimensional data. Neural Networks, IEEE Transactions on, 13(6), 1331-1341.

Rennings, K., \& Rammer, C. (2009). Increasing energy and resource efficiency through innovation: an explorative analysis using innovation survey data. Czech. Journal of Economics and Finance, 59(5), 442-459.

Rosenberg, N., \& Trajtenberg, M. (2004). A general-purpose technology at work: the Corliss steam engine in the latenineteenth-century United States. The Journal of Economic History, 64(1), 61-99.

Saidur, Masjuki, H. H., Jamaluddin, M. Y., \& Ahmed, S. (2007). Energy and associated greenhouse gas emissions from household appliances in Malaysia. Energy Policy, 35(3), 16481657.

Scherer, F. (1982). Interindustry technology flows in the United States. Research Policy, 11, 227-245.

Schumpeter, J. (1942). Capitalism, socialism and democracy. New York: Harper.

Segev, A., \& Kantola, J. (2012). Identification of trends from patents using self-organizing maps. Expert Systems with Applications, 39(18), 13235-13242.

Shane, S. (2001). Technology regimes and new firm formation. Management Science, 47(9), 1173-1190.

Silva Almendra, V., Enăchescu, D., \& Enăchescu, C. (2014). Ranking computer science conferences using selforganizing maps with dynamic node splitting. Scientometrics, 102(17), 1-17.

Squicciarini, M., H. Dernis and C. Criscuolo (2013). Measuring patent quality: indicators of technological and economic value. OECD Science, Technology and Industry Working Papers, 2013/03, OECD Publishing.

Sternitzke, C., Bartkowski, A., \& Schramm, R. (2008). Visualizing patent statistics by means of social network analysis tools. World Patent Information, 30, 115-131.

Tseng, Y. H., Lin, C. J., \& Lin, Y. I. (2007). Text mining techniques for patent analysis. Information Processing \& Management, 43(5), 1216-1247.

Ultsch, A., \& Siemon, H. P. (1990). Kohonen's self-organizing feature maps for exploratory data analysis, in: proceedings of international neural network conference (INNC'90) (pp. 305-308). Dordrecht: Kluwer academic Publishers.

Van Eck, N., \& Waltman, L. (2010). Software survey: VOSviewer, a computer program for bibliometric mapping. Scientometrics, 84(2), 523-538.

Van Eck, N.J., \& Waltman, L. (2014). Visualizing bibliometric networks. In Y. Ding, R. Rousseau, \& D. Wolfram (Eds.), Measuring scholarly impact: Methods and practice. Springer (pp. 285-320)

Verspagen, B. (1997). Measuring intersectoral technology spillovers: estimates from the European and US patent office databases. Economic Systems Research, 9, 47-65.

Verspagen, B. (2007). Mapping technological trajectories as patent citation networks: a study on the history of fuel cell research. Advances in Complex Systems, 10(01), 93-115.

Vesanto, J. (1999). SOM-based data visualisation methods. Intelligent Data Analysis, vol., 3, 111-126.

Vesanto J., Himberg J., Alhoniemi E., Parhankangas J. (1999). Self-organizing map in Matlab: the SOM Toolbox. In Proceedings of the Matlab DSP conference 99:16-17.

White, H. D., Lin, X., \& McCain, K. W. (1998). Two modes of automated domain analysis: multidimensional scaling vs 
Kohonen feature mapping of information science authors. Advances in. Knowledge Organization, 6, 57-63.

Yoon, B. P. Y. (2004). A text-mining-based patent network: analytical tool for high-technology trend. Journal of high technology management research, 15, 37-50.
Yoon, B.-U., Yoon, C.-B., \& Park, Y.-T. (2002). On the development and application of a self-organizing feature map-based patent map. RD Management, 32(4), 291-300. 